\title{
Factors associated with treatment outcome of acute post streptococcal glomerulonephritis among patients less than 18 years in Mekelle City, Public Hospitals, North Ethiopia
}

\author{
Lemlem Gebreselassie Gebreyesus ${ }^{1 *}$, Atsede Fantahun Aregay ${ }^{2}$, Kahsu Gebrekirstos Gebrekidan² \\ and Yisak Hagos Alemayehu'
}

\begin{abstract}
Objective: To assess factors associated treatment outcomes of acute post streptococcal glomerular nephritis among patients less than 18 years old in Mekelle City Public Hospitals.

Results: About 334 medical records c of children with acute post streptococcal glomerular nephritis were revised during the study period. Of these 244 (73.1\%) had a positive outcome. acute post streptococcal glomerular nephritis was found to be statically significant associated with age $<5$ years, duration of infection, the source of infection and length of stay in Hospital.
\end{abstract}

Keywords: Acute post-streptococcal glomerular nephritis, Risk factors, Children

\section{Introduction}

Acute post-streptococcal glomerulonephritis (APSGN) is an immune-mediated disease associated with acute respiratory tract infections and skin infections by $\beta$-hemolytic Streptococcus group A bacteria with clinical manifestation of edema, gross hematuria hypertension, proteinuria and oliguria persist more than 3 weeks [1]. Post-streptococcal glomerulonephritis (PSGN) is most common in children aged 5-12 years but not common before the age of 3 years. The most common acute glomerulonephritis is PSGN which is found mostly in developing countries and affecting more children than adults and leading to acute kidney injury, and potentially increasing morbidity in children and threatening life if

*Correspondence: lemimsc09@gmail.com

${ }^{1}$ Ayder Comprehensive Specialized Hospital, Mekelle University, Mekelle, Tigray, Ethiopia

Full list of author information is available at the end of the article delayed diagnosis and subsequently inaccurate treatment [2].

PSGN is reported from all over the world and the rates are higher in children than in adults. The incidence of PSGN in children was 24.3 cases per 100,000 people whereas in people older than 15 years, the estimated incidence is 2 cases per 100,000 people. Despite declining incidence of APSGN in many developed countries, there is still a significant burden in developing countries [3].

Regardless of the reduction in the worldwide incidence of PSGN, epidemics and clusters of cases of PSGN continue to appear. PSGN primarily affects children, aged 2-12 years in epidemic cases, with $10 \%$ in those below 2 years of age [4]. Prevalence of PSGN in the developing countries is still high, but its incidence declines in the industrial countries. Prognosis of APSGN is generally good; especially PSGN in children has a good outcome [5]. APSGN is principally diseases of poverty, because overcrowding and poor hygiene are prevailing which 
are the significant causes of morbidity and mortality in developing countries with low socioeconomic status [6].

The global prevalence of APSGN in is low particularly in industrialized nations because of easier and earlier access to competent medical treatment of streptococcal infections. The widespread use of fluorination of water was other factor because virulence factors in Streptococcus pyogens are reduced with fluoride exposure [7].

Most incidents of acute glomerulonephritis appear to be associated with a post-infectious state with known etiological agents [10]. It is known that the incidence of PSGN has recently decreased considerably in the developed world; the global burden of the disease has been less well quantified. Studies showed that PSGN incidence has fall insubstantially in Europe, South America \& Asia. However, the disease may still cause substantial burden in indigenous communities and in poor, rural parts of developing countries such as Africa [8, 9].

Different studies reported PSGN patients developed different complications such as prolonged hypertension pulmonary edema, renal failure and proteinuria later in the clinical course and it needs early detection, early treated and prevention of source of infection like a sore throat and skin infection [1]. Though post-streptococcal complications are known to be common among Ethiopian children, but little is known about the morbidity and mortality associated with APSGN. Therefore, the aim of the study was to assess factors associated treatment outcome and of acute post-streptococcal glomerulonephritis among children less than 18 years old.

\section{Main text Methods}

Hospital based retrospective cross-sectional study was conducted in Mekelle city which is the capital city of Tigray National Regional state, Ethiopia. All children less than 18 years who were admitted with a diagnosis of APSGN in the pediatric ward who had complete medical record in Ayder comprehensive specialized hospital \& Mekelle Hospital from September 2013-August 2015 were included in the study. The sample size was 334 which was calculated using single proportion formula. A de-identified data from patient's charts was used. Client's chart was selected using simple random sampling based on the sampling frame prepared from Medical record of patients from Ayder comprehensive specialized hospital and Mekelle hospital. Structured checklist developed from different literature was used to collect data. The tool was pre tested in $10 \%$ of similar population which was not included in the study. Correction was done to the wording and other issues. To minimize bias, the data collectors were not employee of the hospitals included in the study. The collected data was checked for completeness and consistency before data entry and analysis. The data was coded and entered to Epi-info then, exported to SPSS version 20 for analysis. Descriptive statistics was computed, bivariate and multivariable logistic regressions were calculated to analyze the relationship between the dependent and independent variables. Association between variables were checked by considering p-value of 0.05 or less as the cut-off point for bivariate \& multivariate regressions. Tests and tables were used to present the result.

\section{Results}

\section{Socio-demographic characteristics}

A total of 334 records of children diagnosed with APSGN was included in this study. Most affected age group was between 5 and 9 years which was one hundred forty-two (42.5\%). The age range of the participant patients was between 2 and 17 years with mean age of 8.6 years more $(60.5 \%)$ of the study participants were males. Two hundred fifty-eight (77.2\%) patients were from rural areas. The infection occurred during the dry and rainy seasons (Table 1).

\section{Clinical presentations}

The most common chief complaints were body swelling 274 (82\%) and hematuria 180 (53.9\%). Two hundred eighty-two (84.4\%) children were undernutrition according to the World Health Organization (WHO) parameter of nutritional status. About 258 patients came to Hospital later than 2 weeks of APSGN infection and $76(22.8 \%)$ came as early as early 2 weeks and most of patients (77.2\%) stayed in Hospital for longer than 2 weeks. The maximum length of stay in hospital was 62 days and minimum length of stay was 3 days. Hypertension was the most common complication which was developed by 214 (64.1\%) patients (Table 1).

\section{Laboratory indications}

For all APSGN patient's urinalysis was done for microscopic hematuria and protein urea. Both hematuria\& protein urea were found in two 218 (65.3\%), azotemia or nitrogen urea in blood found in $173(51.8 \%)$ children, hyperkalemia and $158(47.3 \%)$ children. ASO titer was done for 68 patients only and persistent microscopic hematuria could persevere up to 1-2 years after the initial presentation (Table 2).

\section{Pharmacological treatments}

In this study, all patients were treated with either oral or parenteral furosemide. Two hundred and two (63.5\%) patients took additional antihypertensive drugs such as Nifedipine, Hydralazine. Similarly, one hundred and forty-three (42.8) patients took antibiotics for the 
Table 1 Demographic characteristic and clinical presentation of children $<18$ years with PSAGN at comprehensive Specialized Hospital and Mekelle Hospital Mekelle. 2013-2015 $(n=334)$

\begin{tabular}{|c|c|c|c|}
\hline Variables & Category & Frequency & $\%$ \\
\hline \multirow[t]{4}{*}{ Age in year } & $<5$ years & 49 & 14.7 \\
\hline & $5-9$ years & 142 & 42.5 \\
\hline & $10-14$ years & 131 & 39.2 \\
\hline & $15-18$ years & 12 & 3.6 \\
\hline \multirow[t]{2}{*}{ Sex } & Male & 202 & 60.5 \\
\hline & Female & 132 & 39.5 \\
\hline \multirow[t]{2}{*}{ Residential area } & Urban & 76 & 22.8 \\
\hline & Rural & 258 & 77.2 \\
\hline \multirow[t]{2}{*}{ Season of infection } & Dry & 171 & 51.2 \\
\hline & Rainy & 163 & 48.8 \\
\hline \multirow[t]{4}{*}{ Reasons for presentation ${ }^{a}$} & General body swelling & 274 & 82 \\
\hline & Facial swelling & 60 & 18 \\
\hline & Bloody urine & 180 & 53.9 \\
\hline & Oliguria & 114 & 34.1 \\
\hline \multirow[t]{2}{*}{ Nutritional status } & Well nourished & 52 & 15.6 \\
\hline & Under nourished & 282 & 84.4 \\
\hline \multirow[t]{2}{*}{ Duration of infection } & Early (<2 weeks) & 58 & 17.4 \\
\hline & Late (>2 weeks) & 276 & 82.6 \\
\hline \multirow[t]{3}{*}{ Source of infection } & Sore throat & 181 & 54.2 \\
\hline & Skin infection & 110 & 32.9 \\
\hline & No history of infection & 43 & 12.9 \\
\hline \multirow[t]{2}{*}{ Length of hospitalization } & $<2$ weeks & 76 & 22.8 \\
\hline & $>2$ weeks & 258 & 77.2 \\
\hline \multirow[t]{5}{*}{ Complications $^{\mathrm{a}}$} & Hypertension & 214 & 64.1 \\
\hline & Encephalopathy & 56 & 16.8 \\
\hline & Heart failure & 78 & 23.4 \\
\hline & Pulmonary edema & 60 & 18 \\
\hline & Renal failure & 22 & 6.6 \\
\hline
\end{tabular}

${ }^{a}$ More than one answer was possible

treatment of infection before presenting to hospital. In this study, the common anti-hypertensive drug next to furosemide was nifedipine which was taken by 178 (53.3\%) patients (Table 2).

\section{Treatment outcome of APSGN}

Two hundred forty-four (73.1\%) recovered immediately (positive outcome) and ninety (26.9) had negative outcome (20 died and 70 had follow-up) (Table 2).

\section{Factors associated with treatment outcome of APSGN}

In bivariate analysis age, place of residence, clinical future, nutritional status, duration of infection, source of infection and length of stay in hospital had association with outcome of acute post-streptococcal glomerulonephritis. Whereas, in multivariate logistic regression age,
Table 2 Laboratory Findings and management of Children With PSAGN Ayder compressive specialized Hospital and Mekelle Hospital Mekelle. 2013-2015 $(n=334)$

\begin{tabular}{llrr}
\hline Variables & Category & Frequency & \% \\
\hline Urine analysis & Hematuria & 103 & 30.8 \\
& Proteinuria & 13 & 3.9 \\
& Both & 218 & 65.3 \\
Hyperkalemia & Yes & 158 & 47.3 \\
& No & 176 & 52.7 \\
Anti-Streptococcal O & Positive & 41 & 12.3 \\
(ASO) titer & Negative & 27 & 8.1 \\
& Not done/not doc. & 266 & 79.6 \\
Critinin level (during & Normal<1.2 mg/dl & 273 & 81.7 \\
discharge) & High $\geq 1.2 \mathrm{mg} / \mathrm{dl}$ & 39 & 11.7 \\
& Not done & 22 & 6.6 \\
Blood Urea Nitrogen & Normal 7-20 mg/dl & 265 & 79.3 \\
(BUN) during discharge & High > 20 mg/dl & 46 & 13.8 \\
& Not done & 23 & 6.9 \\
Dialysis & Yes & 9 & 2.7 \\
& No & 325 & 97.3 \\
Pharmacological man- & Antibiotics & 143 & 42.8 \\
agement & Diuretics & 332 & 99.4 \\
& Anti hypertensive & 334 & 100 \\
Type of antihypertensive & Nifidipine & 178 & 53.3 \\
drugs & Enalaprile & 34 & 10.2 \\
& Others & 122 & 36.5 \\
Treatment outcome & Positive & 244 & 73.1 \\
& Negative & 90 & 26.9 \\
\hline
\end{tabular}

duration of infection, source of infection and length of stay were statically associated with acute post-streptococcal glomerulonephritis. Children less than 5 years old were four times at greater risk of APSGN than children older than 5 years $[\mathrm{AOR}=4.593$ with $95 \%$ CI $(1.013-$ $20.811)]$. Children with duration of infection greater than 2 weeks were 4 times at greater risk than those who had duration of infection less than 2 weeks $[\mathrm{AOR}=4.314$ with 95\% CI (1.101-15.491)], Children with evident source of infection had negative outcome as compared to those who had no evident source of infection $[A O R=3.909$ with 95\% CI (1.747-8.746)]. Length of stay in hospital was statistically associated with negative outcome of APSGEN, children who had hospital stay of greater than 2 weeks had negative out come as compared with those who had hospital stay of less than 2 weeks $[\mathrm{AOR}=4.456$ with 95\% CI (2.426-8.184)] (Table 3).

\section{Discussion}

Mortality and morbidity are the negative outcomes of APSGN which are known to be high in developing countries. In this study $244(73.1 \%)$ patients had recovered 
Table 3 Factors associated with PSAGN at Ayder comprehensive specialized Hospital and Mekelle Hospital Mekelle. 2013-2015 $(n=334)$

\begin{tabular}{|c|c|c|c|c|}
\hline \multirow[t]{2}{*}{ Variables } & \multicolumn{2}{|l|}{ Outcome } & \multirow[t]{2}{*}{ COR $95 \% \mathrm{Cl}$} & \multirow[t]{2}{*}{ AOR $95 \% \mathrm{Cl}$} \\
\hline & Positive & Negative & & \\
\hline \multicolumn{5}{|l|}{ Age (years) } \\
\hline$<5$ & $39(79.6 \%)$ & $10(20.4 \%)$ & $3.900(1.034-14.714)$ & $4.593(1.013-20.811)^{* *}$ \\
\hline $5-9$ & $114(79.2 \%)$ & $30(20.8 \%)$ & $3.800(1.143-12.628)$ & $2.865(0.735-11.178)$ \\
\hline $10-14$ & 85 (67.9\%) & $44(34.1)$ & $1.932(0.588-6.342)$ & $1.510(0.399-5.714)$ \\
\hline $15-18$ & $6(50 \%)$ & $6(50 \%)$ & 1.00 & 1.00 \\
\hline \multicolumn{5}{|l|}{ Residential area } \\
\hline Urban & $63(82.9 \%)$ & $13(17.1 \%)$ & 1.00 & 1.00 \\
\hline Rural & $181(70.2 \%)$ & $77(29.8 \%)$ & $0.485(0.252-0.933)$ & $0.580(0.277-1.214)$ \\
\hline \multicolumn{5}{|l|}{ Clinical } \\
\hline General body swelling & $191(69.7 \%)$ & $83(30.3 \%)$ & $0.304(0.133-0.696)$ & $0.480(0.190-1.211)$ \\
\hline Facial swelling & 53 (88.3\%) & $7(11.7 \%)$ & 1.00 & 1.00 \\
\hline \multicolumn{5}{|l|}{ Nutritional status } \\
\hline Well nutrition & 31 (59.6\%) & $21(40.4 \%)$ & 1.00 & 1.00 \\
\hline Under nutrition & $213(75.5 \%)$ & $69(24.5 \%)$ & $2.091(1.128-3.875)$ & $0.451(0.116-1.750)$ \\
\hline \multicolumn{5}{|l|}{ Duration of infection } \\
\hline Less than 2 weeks & $33(56.9 \%)$ & $25(43.1 \%)$ & 1.00 & 1.00 \\
\hline Greater than 2 weeks & $211(76.4 \%)$ & $65(23.6 \%)$ & $2.459(1.364-4.434)$ & $4.314(1.201-15.491)^{* *}$ \\
\hline \multicolumn{5}{|l|}{ Source of infection } \\
\hline Yes & $226(77.7 \%)$ & $65(22.3 \%)$ & $4.829(2.482-9.397)$ & $3.909(1.747-8.746)^{* *}$ \\
\hline No & 18 (41.9\%) & $25(58.1 \%)$ & 1.00 & 1.00 \\
\hline \multicolumn{5}{|c|}{ Length of stay in hospital (weeks) } \\
\hline$<2$ & $33(43.4 \%)$ & $43(56.6 \%)$ & 1.00 & 1.00 \\
\hline$>2$ & $211(81.8 \%)$ & $47(18.2 \%)$ & $5.850(3.365-10.168)$ & $4.456(2.426-8.184)^{* *}$ \\
\hline
\end{tabular}

** Highly significant in AOR and p-value $<0.05$

from their illness immediately (positive outcome), whereus 90 (26.9\%) had not recovered immediately (negative outcome). This was less as compared to the study conducted in Athens, Greece in which complete clinical and morphological recovery was observed in $92 \%$ children who had APSGN [10]. This finding was different as compared to a study done in Raze Ekman Hospital, Iran in which no mortality rate was reported during the study period [11, 12]. Whereas according to American Journal of nephron, in a Hospital in Turkey death was occurred in 20 to $25 \%$ of patients. Similarly, in a study conducted in Sudan Khartoum Hospital in 2012, 66\% patients recovered from APSGN. The possible reasons for the difference in these findings might be because more complication was developed before presenting to hospital or health facility due to lack of infrastructure, not giving less priority to their disease and miss diagnosis of the disease.

Children who presented late with APSGN to hospital were $82.6 \%$ while only $17.4 \%$ children come early. In contrast to this finding, a study conducted in South Carolina found that, only 33\% participants with PSGN [13] diagnosed lately. This might be due to the difference in socio economic status of the countries and difference in awareness of patients towards health care seeking behavior.

In this study, the time of presentation to hospital was statically significant with the outcome of APSGN $[\mathrm{AOR}=4.314 \quad(95 \%$ CI $(1.201-15.491)]$. Children present to hospital lately were four times at high risk to the negative outcome of APSGN. This is because late diagnose might lead to complication and severity which make them more exposed to mortality and morbidity. Delay in diagnosis or miss in diagnosing is common in children with PSGN, especially if visible hematuria is not a presenting complaint [13].

This study also found that, length of stay in hospital for greater than 2 weeks was statistically significant with negative outcome of APSGN [AOR $=4.456(95 \%$ CI (2.426-8.184)]. As a result, children hospitalized for longer than 2 weeks $f$ had four times higher risk of negative outcome than children who was admitted for less than 2 weeks. About 77.2\% children admitted in hospital for $>2$ weeks and the maximum length of stay in hospital was 62 days and the minimum stay was 3 days. This was in line with a study conducted in Malaysia which 
found that the shortest hospitalization was 4 days, while the longest was 66 days [14]. Another study conducted in Iran showed that the hospital stay of children with APSGN was range $2-26$ days [12]. This variation might be due to difference in socioeconomic status, time gap and design of the study.

This study found that sore throat was the source of infection for $54.2 \%$ of children presented with APSGN and only $12 \%$ children had no past history (source) of infection. Whereas, a study conducted in Chile showed, skin infection was the likely source of 32 participants and only 5 participants had no past history (source) of infection [15].

In this study source of infection was 4 times high risk factors to negative outcomes of APSGN [AOR 3.909 with 95\% CI (1.747-8.746)]. This was similar with a study done in Northern Territory, Australia that indicates social and environmental factors as risk factors of APSGN [16]. It is likely that overcrowding, lack of access to adequate water, heat, humidity, poor education and implementation of personal hygiene are all contributing factors to the risk of infection.

\section{Conclusion}

In conclusion, From the total number of patients treated for post-streptococcal glomerulonephritis, $73.1 \%$ recovered immediately. The most common presentation/ chief complaint was generalized body swelling. More than three-quarters of the patients have prolonged hospitalization for $>2$ weeks and the common complication reported was Hypertension. The risk factors of APSGN in children was age, duration of infection source of infection and length of stay in the hospital. Since Ethiopia is one of the developing countries and there is high risk of skin and respiratory infections.

\section{Limitations}

Some information about the clinical features and laboratory data in these patients was not available. Some patients discontinue long term follow-up and the end outcome was unknown.

\section{Abbreviations \\ AOR: Adjusted Odds Ratio; APSGN: acute poststreptococcal glomerulone- phritis; ASO titer: anti streptococcal O titer; BUN: Blood Urea Nitrogen; PSGN: poststreptococcal glomerulonephritis; SPSS: Statistical Package for Social Sciences; WHO: World Health Organization.}

\section{Authors' contributions}

LGG was the principal investigator of the study; made substantial contributions in conception selecting design, data collection as well as analysis and interpretation of data. AFA was the supervisor of the research; participated in designing and managing data collection and analysis. KGG and YHA involved in drafting and revising critically the manuscript. All authors given final approval of the version to be published. All authors also agreed to be accountable for all aspects of the work in ensuring that questions related to the accuracy or integrity of any part of the work are appropriately investigated and resolved. All authors read and approved the final manuscript.

\section{Author details}

${ }^{1}$ Ayder Comprehensive Specialized Hospital, Mekelle University, Mekelle, Tigray, Ethiopia. ${ }^{2}$ School of Nursing, College of Health Science, Mekelle University, Mekelle, Tigray, Ethiopia.

\section{Acknowledgements}

My gratitude goes to Mekelle University Ayder referral hospital and Department of Nursing for the provision of such a golden opportunity in my educational career. I would like to thank the data collectors and Mekelle and Ayder Referral Hospital medical records department staffs for their dedication and support in the data collection process.

\section{Competing interests}

The authors declare that they have no competing interests.

\section{Availability of data and materials}

All the data is presented in the main manuscript. Raw data can be obtained through an email to the principal author.

\section{Consent to publish}

Not applicable.

\section{Ethics approval and consent to participate}

Clearance obtained from Mekelle University, College of health sciences, Institutional review board. Official letter of support was written from department of nursing to the respected hospitals and confidentiality of the medical record was maintained throughout the study.

\section{Funding source}

The authors have not received any funding or benefits from industry or elsewhere to conduct this study.

\section{Publisher's Note}

Springer Nature remains neutral with regard to jurisdictional claims in published maps and institutional affiliations.

Received: 13 August 2018 Accepted: 25 September 2018

Published online: 01 October 2018

\section{References}

1. Smith J, Faizan M, Eddy A. The child with acute nephritic syndrome. Clinical pediatric nephrology. 3rd ed. Oxford: Oxford University Press; 2003. p. 336-79.

2. Lamesgnaw M, Shimelis D. Outcome of children with acute poststreptococcal glomerulonephritis in Tikur Ambessa specialized teaching hospital. Ethiopian J Pediatr Child Health. 2012;8:1-16.

3. Rodriguez-Iturbe B, Musser JM. The current state of poststreptococcal glomerulonephritis. J Am Soc Nephrol. 2008;19(10):1855-64.

4. Zhang Y, Shen Y, Feld LG, Bruder Stapleton F. Changing pattern of glomerular disease at Beijing children's hospital. Clin Pediatr. 1994;33(9):542-7.

5. Yap HK, Chia KS, Murugasu B, et al. Acute glomerulonephritis-changing patterns in Singapore children. Pediatric Nephron. 1990;4:482-4.

6. Roy RR, Laila K. Acute post-streptococcal glomerulonephritis in children. Bangladesh J Child Health. 2014;38(1):32-9.

7. Carpets J, Steer A, Mulholland E, Weber M. The global burden of group A streptococcal diseases. Lancet Infect Dis. 2005;5(11):685-94.

8. Elson T, Ault B, Jones D, Chesney R, Wyatt R. Post-streptococcal acute glomerulonephritis in children: clinical features and pathogenesis. Pediatr Nephrol. 2011;26(2):165-80

9. Sotsiou F. Post infectious glomerular nephritis Department of Histopathology, Evangelismos Hospital, Athens, Greece. Nephrol Dial Transplant. 2001;16(Suppl 6):68-70.

10. Jackson J, et al. Global burden of post-streptococcal glomerulonephritis. Trop Med Int Health. 2011;16(1):2-11. 
11. Derakhshan A, Hekmat VR. Acute glomerulonephritis in Southern Iran. Iran J Pediatr. 2008;18(2):143-8.

12. Lyndon L, Key J. Short-term prognosis of APSGN in children, Medical University of South Carolina, Charleston. 2008; 153(4):560-4.

13. Wong W, Morris MC, Zwi J. Outcome of severe acute post-streptococcal glomerulonephritis in New Zealand children. Pediatr Nephrol. 2009;24(5):1021-6.
14. Koo SE, Hahn H, Park YS. clinical study of APSGN in Korean children Korean. J Pediatr. 2005:48(6):606-13.

15. Becquet $\mathrm{O}$, Pasche J, et al. Acute post-streptococcal glomerulonephritis in children of French Polynesia Hospital. Pediatr Nephrol. 2010;25(2):275.

16. Marshall CS, et al. Acute post-streptococcal glomerulonephritis in the Northern Territory of Australia: a review of 16 years of data and comparison with the literature. Am J Trop Med Hyg. 2011;85(4):703-10.
Ready to submit your research? Choose BMC and benefit from:

- fast, convenient online submission

- thorough peer review by experienced researchers in your field

- rapid publication on acceptance

- support for research data, including large and complex data types

- gold Open Access which fosters wider collaboration and increased citations

- maximum visibility for your research: over $100 \mathrm{M}$ website views per year

At BMC, research is always in progress.

Learn more biomedcentral.com/submissions 